\title{
Anatomical Particularities of Male Reproductive System of Guinea Pigs (Cavia porcellus)
}

\author{
Florin STAN \\ Department of Comparative Anatomy, Faculty of Veterinary Medicine, University of Agricultural Sciences \\ and Veterinary Medicine, Cluj-Napoca, Romania \\ *Corresponding author: flodvm@yahoo.com
}

Bulletin UASVM Veterinary Medicine 72(2) / 2015,

Print ISSN 1843-5270; Electronic ISSN 1843-5378

DOI:10.15835/buasvmcn-vm: 11410

\begin{abstract}
Currently the pet area shares a great diversity by promoting many exotic species and increasingly expanding existing ones, particularly those of small size. To perpetuate these species a decisive role it has integrity and urogenital health. For this reason and in order to obtain more docile animals, influencing their sexual behavior, veterinarian interventions in order to sterilize, or other curative or preventive maneuvers are required. Knowing in detail the morphology of genitourinary apparatus is crucial for a correct surgical approach. The aim of this study is to achieve a detailed anatomical description of the components of male reproductive system in guinea pigs. Regional stratigraphic dissection was applied on 10 subjects. Macroscopically the components of male genitalia were examined.

Wide opening of inguinal ring was present in all subjects. Ovoid testicle shows a well developed epididymus and a considerable amount of surrounding fat tissue. The glans penis is well represented, being present a small os penis within the dorsal surface of the entire length of glans. The seminal vesicles are the most developed sexual accessory glands, having a coiled pattern, blind ended, and stretching until the abdominal cavity. Prostate and coagulating glands are located at the base of seminal vesicles in close relationship. The prostate is composed of two lobes, dorsal and ventral lobe united by a transversal isthmus. Lobulated coagulating glands show pyramidal pattern being located caudal to the bladder. Bulbouretral glands were small, ovoid and lobulated.

Both gonads and accessory sexual glands were well-developed in guinea pigs.
\end{abstract}

Keywords: anatomy, guinea pig, male, reproductive system

\section{INTRODUCTION}

Exotic pets include numerous species belonging to different orders: carnivores, lagomorphs, rodent and many others. Among these, rodenta has a special place due to the high number of species. They represent a significant share of all pets because of their low body weight, gentle character and ease of maintenance, all these based on numerous information available regarding their necessities. All this led to an increasing share of these species as pets, raising the level of addressability with the practitioner in both health problems and counseling owners about reproduction. On the other hand, their usage as experimental model is well known, guinea pigs being chosen as subjects in many studies. However, anatomical data related to the morphology of the reproductive system is scarce in the literature compared to dogs and cats (Barone 2001), which are used as reference in most cases. This justifies the need of knowledge regarding the anatomy of different exotic species to satisfy the need for improvement in nurturing and medical care, especially surgery.

Anatomical particularities of mammalian reproductive system are the result of ontogenetic development, which in males is primarily related to the development and migration of the 
testicles into the scrotum. In rabbit and rodent the inguinal ring remains open through the animal's life (McCracken et al., 2008; Quesenberry and Carpenter 2012). In these cases, testicle displacement is physiological compared to most mammals in which after migration to the scrotum, the inguinal ring closes. The morphology of the reproductive system contains accessory sexual glands alongside essential organs that produce spermatozoa - the testicles. In rodents, these contain the following formations: vesicular glands, coagulating glands, prostate and bulbo-uretral glands with small variations between species. Morphological development of accessory genital glands is influenced by multiple factors: hormonal, environmental, seasonal variations related to reproductive activity during mating season (Pelletier, 2002; Nishino et al., 2004).

The aim of the present study is to achieve a detailed morphological description of the male reproductive system in guinea pigs (Cavia porcellus), the topography of essential reproductive organs and accessory sex glands.

\section{MATERIALS AND METHODS}

A group of 6 male guinea pigs were used, with weights between 380 and 650 grams from breeding farms. The subjects were treated according to Directive 2010/63 /EU of the European Parliament and of the Council on the protection of animals used for scientific purposes and the Institutional Bioethics Committee of University of Agricultural Science and Veterinary Medicine approved the study. Euthanasia was performed by inhaling an overdose of Isoflurane (Baxter Health Care Corporation, USA). The subjects were positioned in dorsal decubitus performing the extension and fastening of thoracic and pelvine members. The abdominal cavity was opened by performing an incision along the white line until reaching the pubis. The digestive organs which presented topographical relations with components of the reproductive system were identified and then removed to achieve a clearer visualization. After in situ photography the genital apparatus has been removed from the pelvic cavity, identifying each component. The terms were in agreement with NAV 2012.

\section{RESULTS AND DISCUSSION Testicles and sperm ducts (Testis, ducti genitalis )}

In examined subjects the testicles were located in the perineal region, on both sides of the urethra opening. The slightly flatened aspect of testicular bursa (Bursae testis) was more visible due to brown coloring of the skin in the projection region (Fig. 1). After incision and sectioning of regional skin, the testicles were well visualized because their extraabdominal location, being enclosed in a significant ammount of adipous tissue. In contact with the ventral abdominal wall, between the ventral musculature of the abdominal wall and the skin, the ovoid testicles were dorso-lateral oriented with a slight ventro-medial tilt (Fig. 1). Sectioning of the external layers has highlighted the pink colored testicles, with a dorso-laterally located epididimus (Epididymis). The epididimus components (head, body and tail) were easily identified due to their well development. The head of the epididymus (Caput epididymis), was very coiled and covered with adipous tissue being continued through the epididimus body ventrally positioned by deferent ducts. The tail of
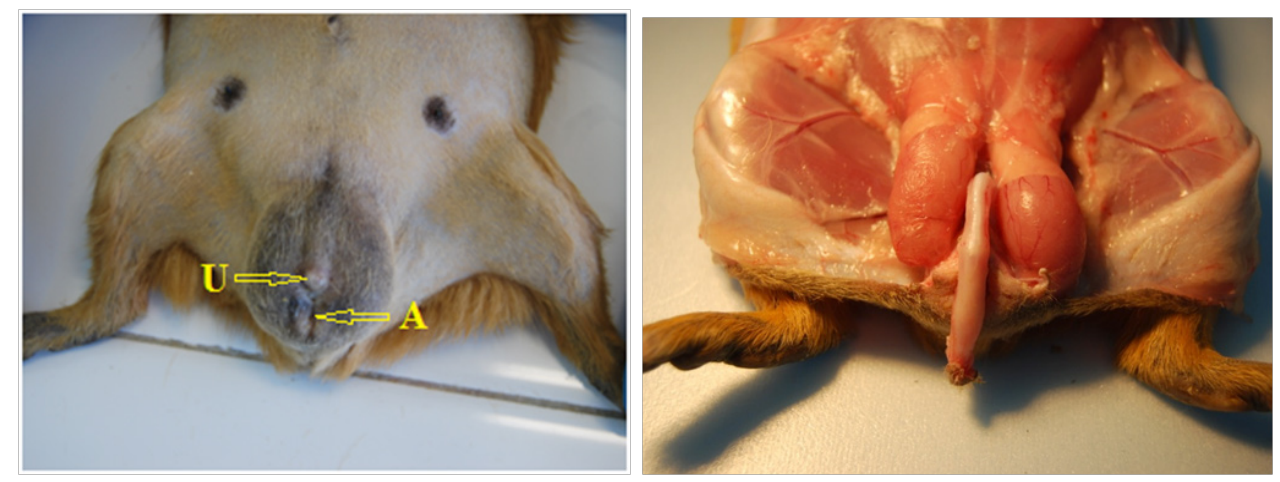

Fig. 1. External appearance of testicular bursa with urethral orifice (U) located cranial to the anus (A)-left and oval shape of testicles-right, in guinea pigs 
the epididymus was very obvious due to excesive coiling being continued by the deferent duct (Ductus deferens) of 1-2 mm diameter (Fig. 2). The ductus deferens presented a relatively tortuous route in the proximal segment, later to become approximately $1.5-2.5 \mathrm{~mm}$ in diameter. Whitish, the paired vas deferens were well visualized due to outline clear, smooth and relatively straight path (Fig. 2). Before opening the urethra, the ducts showed a slight enlargement in size and a very short common route. Testes sizes were between $20-30 \mathrm{~mm}$ long and $12-18 \mathrm{~mm}$ cross section.

\section{Accessory sex glands}

We identified the following accessory sex glands in all subjects: seminal vesicles (Glandulae veziculares), coagulating glands, prostate glands (Glandula prostata) and bulbourethral glands ( Glandula bulbourethralis).

The seminal vesicles showed a particular pattern being tubiform, cylindrical and vermiform, blind ended, well developed, having the largest size of the accessory sex glands with a length between $100-120 \mathrm{~mm}$ and $5-14 \mathrm{~mm}$ large. Located dorsal to the bladder and ventral to the ureters the vesicular glands presented an upward path surpassing the pelvic cavity directing deep in the abdominal cavity. The distal segments were positioned on both sides of the descending colon (Fig. 3). Each vesicular gland presented a broad and well vascularised ligament. The opening of vesicular glands was made median in uretra into a median cleft (colliculus seminalis) together with the ductus deferens opening.

Caudal to the bladder in all subjects we identified the pair coagulating glands, with pyramidal shape, lobulated, being disposed latero dorsal near the seminal vesicles (Fig. 4). Also, these glands were directly related to the prostate gland, being arranged cranio-dorsal to the dorsal lobe of the prostate.

The prostate gland was located immediately caudal to the bladder neck, caudo medial to the coagulating glands and lateral to the seminal
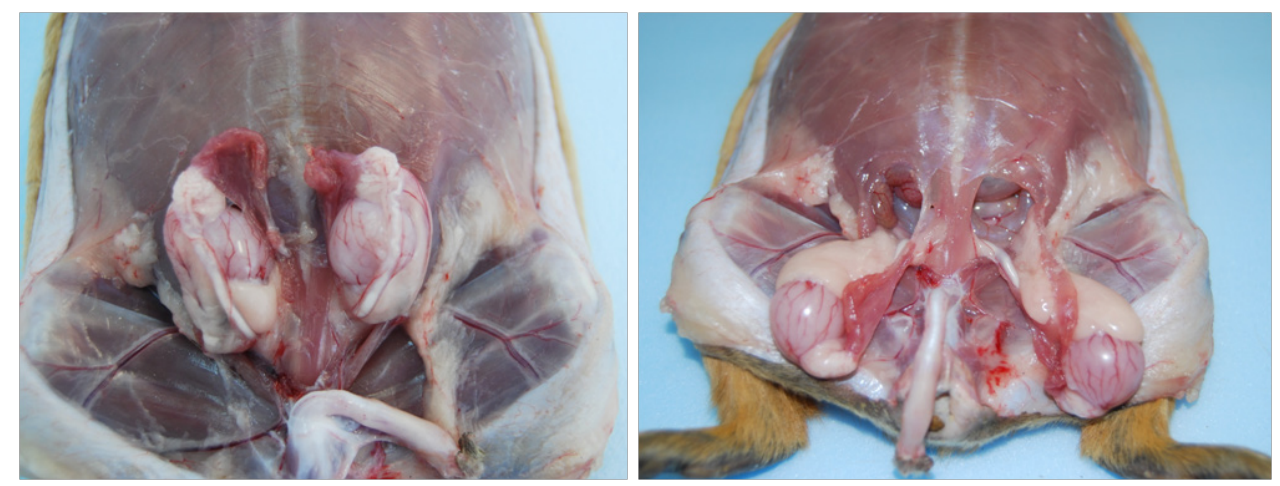

Fig. 2. Oval shape of testicles and clear visualization of deferens ducts and epididymus tail - left and the presence of a large amount of fat on cranial pole of testicles and large inguinal rings - right.
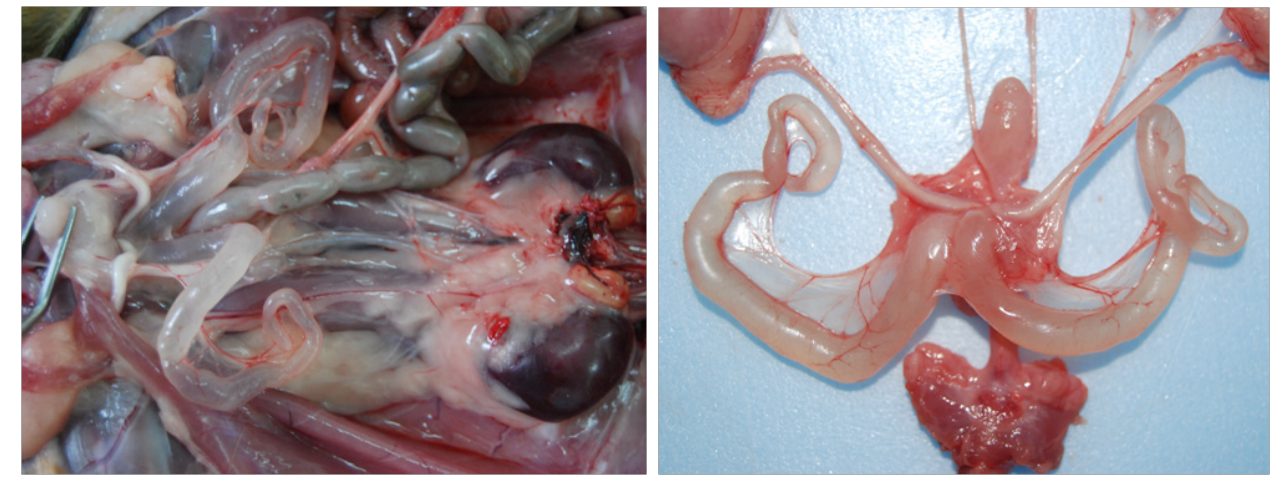

Fig. 3. The tubiform blind ended appearance of vesicular glands located dorsal to the bladder and deferens ducts - left and a well developed ligament of each vesicular gland - right. 
vesicles basically being surrounded between the specified components, in its turn surrounding the urethra (Fig. 4). Larger dorsal lobe was joined by a small isthmus to the ventral lobe, smaller in size. Prostate gland with coagulating glands appeared like a common structure without presenting a joint capsule (Fig. 4).

Bulbourethral glands, small, have been identified on both sides of the urethra, on the ischial arch segment of the urethra, ventral to the rectum and dorsal to the pubic symphysis (Fig. 4).

In the initial segment, the penis was attached to the ischiatic arch by the ischio-cavernous muscle while the distal segment was included in the prepuce. Two portions of the penis were recognized: the penian body and glans both of the same calibre with lengths between $45-85 \mathrm{~mm}$ and $4-7 \mathrm{~mm}$ circumference. The junction of the two segments was well individualized (Fig 5). The penis was " $\mathrm{S}$ "-shaped. We also identified a penian os situated dorsally along the penian glans. In its retracted position the penis was situated ventrally to the pubic symfysis, between the latter and skin. Along all the penis glans until the uretral ostium we identified prominences like small spurs arranged in parallel lines situated dorso-laterally and ventrally, with the ones in the dorsal region having a discontinuous aspect opposed to the ones in the ventral region which were continuous.

In the ventral side of the penis, ventrally from the extrapelvine urethra, in the caudal segment of the penis, we identified the presence of an intormittent sac which open in a transversal slit, caudally from the urethral ostium (meatus). Inside this formation two slightly curved downwards keratinaceous styles were identified. Their insertion was at the cranial segment of the intromittent sac. In living subjects a slight pressure on the penis base lead to its externalization.

\section{DISCUSSION}

The variety of information related to the reproductive system of domestic animals is already recognized taking into account the commercial or

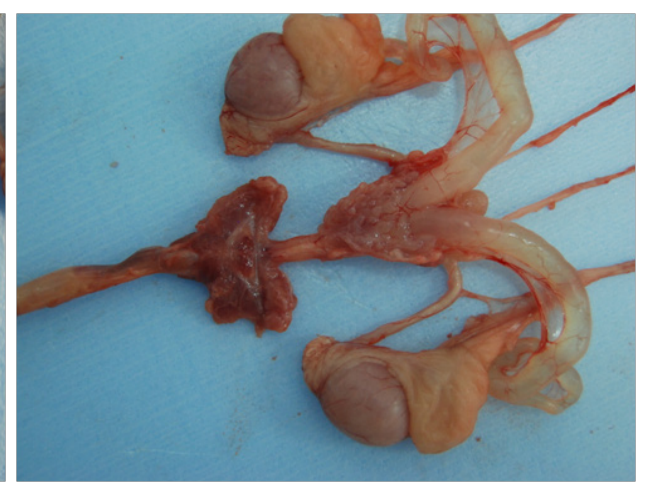

Fig. 4. The prostate gland topography and the coagulating glands - left. The prostate and coagulating glands compose a single structure without a common capsule - right. The topography of bulbourethral glands caudally to the prostate - right.
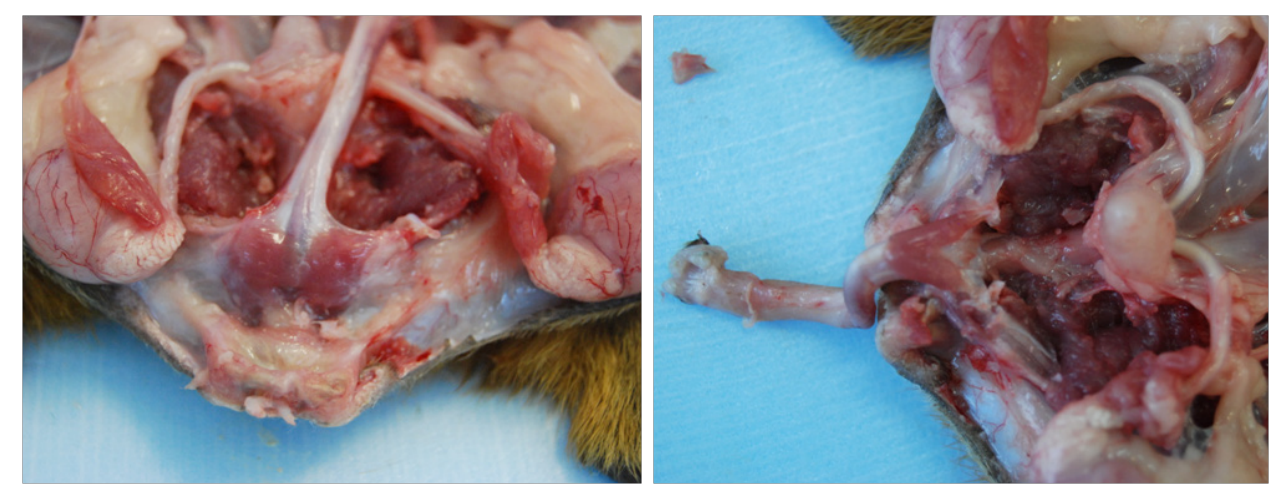

Fig. 5. The guinea pigs penis and its ischio cavernous muscle attachment - left and the S shape of penis - right. 
productive aspect. However, the morphological descriptions of the reproductive system of exotic species used as pets or as experimental models are relatively few. From all this, rodents and lagomorphs, especially mice, rats and rabbits receive more attention because they are used in various medical experiments (Vasquez and Del Sol 2002 Suckov et al., 2005; Knoblahgh and True, 2011). Reproductive components are relatively similar in mostspecies and include principal organs - testes, spermatic ducts and accessory sex glands (Barone 2001). Development of these components is influenced by various factors such as hormone composition and androgenic stimulation being of the highest importance (Cepeda et al., 2006). Other factors include the components itself, namely the presence or absence. In the latter scenario, the remaining organs take over the function of the missing one. Environmental factors, time of year and mating season also influence the morphology and function of the reproductive apparatus (Gotteich et al., 1998; Nishino et al., 2004; Breed et al., 2014).

Morphology of main organs of the reproductive system in guinea pigs is common with that of other species like cattle, sheep, swine, lagomorphs and even humans. The caudal-lateral orientation and a slight dorso-ventral tilt is common in most rodents and lagomorphs (Barone 2001, Cooper et Schiller, 1975). Also, the extraabdominal topography with the possibility of intraabdominal migration is present in rabbit as well. During fetal development the testicle descent through the inguinal channel into the scrotal pough takes place in two morphologically distinct phases, each controlled hormonally by secretions from the testicles themselves, with direct implication upon the gubernaculum testis. From the caudadl pole of the kidney, the testicles migrate through the inguinal channel following the lengthening of the gubernaculums and suspensor ligament regression conditioned by testosterone production (Hutson et al., 2009, 2015).Thus, in some animals the descent is complete since the fetal phase(cattle) or only approaching birth(horse)(Barone 2001). The testicles migration through the life make guinea pigs and rabbit to have functional cryptorchidism The extraabdominal loction of the testicles is of great importance for sperm production because of the low temperature necessary for this process. The control for low temperature maintenance is done by contraction of the dartoic layer and testicular cord which bring closer or take further the testicles from the body.

The guinea pigs epididymis have common characteristics with those of most mammals. The pronounced coiling of head and of the tail of the epididymis is usually found in rat, hamster, chinchilla and in rabbit (Barone 2001). The vast amount of fat covering the head of the epididymis found in guinea pigs and and other rodents is not so well represented in rabbits. Due to this pattern the need of surgical closure of the inguinal ring, in orchiectomy might be controversial. Some authors claim that this amount of fat just might have a protective effect. In our opinion, to prevent postoperative herniation suturing is necessary due to considerable width of the inguinal ring and the possibility of migration of fat from inguinal ring. More over this fat is removed during the orchiectomy. Thus, this anatomical peculiarity of testicles in guinea pigs has direct implications in orchiectomy.

Open or closed surgical approach is the most appropriate for the rodents due to the easy anatomical closure by suturing the inguinal rings which are much broader in guinea pigs than in rabbits. Abdominal laparoscopic approach is appropriate to juveniles or in rodents whose testicles migrate extra-abdominally only in reproductive seasons such as sqiurel or prairie $\operatorname{dog}$ (Linetz 2000).

Accessory sex glands in guinea pigs were the seminal vesicles, coagulating glands,, prostate glands and bulbourethrale glands. In mammals the presence of accessory sex glands is variable, in terms of topography, number, size and especially shape. The largest diversity is found in rodents, the four components being present in rats (Rattus rattus) (Knoblahgh and True, 2011), chinchilla (Chinchilla lanigera) (Cepeda et al., 1999; Calamar et al., 2014) and spoted paca (Agouti paca) (Borges et al., 2014) while in rabbits are found vesicular glands, well-developed prostate and rudimentary bulbourethrale glands which can be observed only ventrally due to their small size (Barone 2001). In capybara only the prostate and vesicular glands were reported (Ferandez et al., 2010). Regardless of the presence or absence of some or other accessory sex glands their topography is the same in all species - the following are attached to the uretra in caudal direction: vesicular glands, 
coagulating glands, prostate and bulbourethral glands.

Our results regarding the tubular, vermiform blind ended and slightly coiled pattern, of vesicular glands are similar to those described in chinchilla (Calamari et al., 2014). The fact that these glands are well represented is due to their function in secretion of seminal fluid as part of the sperm in a range of $50 \%$, both in guinea pigs and chinchilla. Its production is important because in these species after copulation, in the vaginal plug the composition produced by the vesicular glands has a high percentage. Like in rats (Sukov et al., 2005; Knoblahgh and True, 2011), vesicular glands opening in guinea pigs are common with the vas deferens opening compared with the spotet paca which present separate openings of deferents ducts and seminal vesicles (Borges et al., 2014).

The topography of the coagulating gland described in this study, - located latero dorsal to the vesicular glands and craniodorsal to the dorsal lobe of the prostate - is similar to that described in chinchillas (Cepeda et al.,2006) and gerbil (Pinheiro et al., 2003). In rats the coagulating glands are located on the medial sides of the vesicular glands (Knoblahgh and True, 2011) being referred to as anterior prostatic lobes. In rodents the similarity regarding the coagulating glands is related to their close proximity to the prostate gland, even if their opening are at different levels of the urethra (Pinheiro et al., 2003; Quesenberry and Carpenter 2012 ). Domestic species like dog, horse, ram, goat and bull lack coagulating glands (Barone 2001)

In animals, prostate gland description shows the presence of several lobes, compared to man in which the prostate gland is a singular organ (Gray 1918). In chinchilla the presence of two lobes was described, the right and left, dorsal located to the junction of the seminal vesicles with urethra, united by an isthmus (Cepeda et al., 2006; Calamari et al., 2014). These descriptions are similar to our results in guinea pigs, in which the prostate gland was composed of two lobes: a well developed dorsal lobe and a small ventral lobe. Neuhaus et al., 2001 made the same description in guinea pigs using a different terminology: cranial and caudal lobe. In rats, according to Knoblahgh and True, 2011, the prostate gland has four lobes: anterior, dorsal, lateral and ventral, sometimes the dorsal and lateral lobes being identified as the dorsolateral lobe. The dorsal lobe surrounds the urethra while the ventral lobe is arranged below the urethra and caudal to the bladder neck. Due to the similar structure of the coagulating glands with the prostate, these glands are sometimes called the anterior lobe of the prostate, being attached to the lesser curvature of the vesicular glands (Knoblahgh and True, 2011).

The ferret (Mustela putorius) shared the same characteristic regarding the presence of the prostate gland as single organ, considerably increased in size $(1.5 / 0.6 \mathrm{~cm})$, as in humans, surrounding the urethra (Jakobs and Podar, 1986). Moreover, in ferret the prostate is the only accessory sex gland. The most controversial descriptions of the prostate are in rabbits. In this species thr prostate is composed of three parts: proprostata, prostate and paraprostata (Holts and Foote 2005; McCraken et al., 2008). The proprostate is the segment located caudally from the vesicular glands and cranially to the prostate while the prostate and paraprostate are located cranially to the bulbourethral glands. These glandular structures open at the intrapelvine urethra on both sides of the seminal culliculum (Vasquez and Del Sol 2002; ).

The bulbourethral glands in guinea pigs are situated caudally to the prostate, dorsally to the urethra and dorsolaterally to the ischiocavernous muscle. The same topography has been described in rats (Knoblahgh and True, 2011), chinchillas (Cepeda 1999) and agouti (Menezes et al., 2010). A particular aspect of these glands is that they are located more caudally on the urethra, not being in the close proximity of the prostate, as is in humans (Gray 1918; Barone 2001; Knoblahgh and True, 2011). The lobulated, oval shape is common to rats and guinea pigs while in rabbits these glands only have the latter characteristic.

A particularity of the penis in guinea pigs revealed by our study is the presence of the intromittent sac, situated ventrally to the urethra and the two keratinoceous styles whose insertions are cranially in the mentioned structure. During the erection the two keratinoceous styles are externalized. This aspect has been previously reported in guinea pigs (Weir 1974; Cooper and Sdchiller 1995) and agouti (Molineau et al., 2006,2009 ). Also the presence of the small spurshaped formations at the on the penian glans was described in agouti (Molineau et al., 2005) spoted 
paca (Borges et al., 2014) and even cat (Barone 2001). Even if the role of the proeminences on the intermitent sac is not known (Cooper and Schiller 1997) their presence alongside the spurshaped formations anchor the penian gland in the female vagina, contributing to the stimulation of spontaneous female ovulation.

The presence of the penian os is common to guinea pigs, chinchillas, (Cepeda et al., 2006) and rats (Knoblahgh and True, 2011) but not to rabbits in which, on the other hand has been observed a free extremity of the penis (Queensbery and Carpenter, 2004). Also the topography of rabbit's penis is different from the one we observed in guinea pigs, in which the penis is situated between the two testicles. This aspect can be considered an advantage while castrating rabbits due to the possibility the prescrotal approach compared to guinea pigs for which two incisions are necesary.

A complete description including histological research on the reproductive system in guinea pigs is the subject of another ongoing study which will be published in the future.

\section{CONCLUSION}

The morphology of the genital apparatus in guinea pigs shows many similarities with that of rodents.

In guinea pigs the position of the testicles in scrotal pouches without an obvious scrotum, their oval shape and overall conformation and topography is common to that of rats, chinchillas, rabbits, ferrets and other rodets.

The open state of the inguinal canal throughout all their lifespan, allows the intraabdominal migration of the testicles, similar to rabbits.

In guinea pigs the accessory genital glands are: vesicular, coagulanting, prostate and bulbourethral.

The vesicular glands are well represented with a vermiform aspect similar to chinchillas, extending deep into the abdominal cavity.

The prostate has two lobes: a well-developed dorsal one and a smaller ventral one.

Presence of the intromitent sac is unique to histricomorphs.

\section{REFERENCES}

1. Barone R (2001). Splanchnologie II. In: Anatomie comparée des mammifères domestiques. Tome quatrième, Triosième edition, Paris, 242.
2. Borges EM, Branco E, Lima AR, Leal LM, Leandro Luiz Martins LL, Reis ACG, Cruz C, Machado MRF, Miglino MA (2014). Morphology of accessory genital glands of spotted paca (Agouti paca Linnaeus, 1766). Animal Reproduction Science 145:75-80.

3. Breed WG, Leigh CM, Aplin KP, Shahin AAB, Avenant NL (2014). Morphological diversity and evolution of the spermatozoon in the mouse-related clade of rodents. J Morphol 275:540-547.

4. Calamar CD, Patruica S, Dumitrescu G, Bura M, Dunea IB, Nicula M (2014). Morpho- histological studies on the male genital apparatus of Chinchilla laniger. Scientific Papers Animal Science and Biotechnologies 47(1):275280.

5. Cepeda C, Raquel Adaro A, Luis Y Penailillo G Paola (2006). Variaciones Morfométricas de la Próstata de Chinchilla laniger (MOLINA, 1982) y de la Concentración de Testosterona Plasmática Durante un Ciclo Reproductivo Anual. Int J Morphol [online] 24(1):89-97.

6. Cepeda R, Adaro L, Penailillo P, Orostegui C (1999). Variaciones morfologicas e stacionales de las glandulas bulbouretrales de la chinchilla (Chinchilla laniger), en cautiverio. Rev Chilena Anatom 17 :59-66.

7. Cooper G, Schiller AL (1975). Anatomy of the Guinea Pig. Harvard University Press, Cambridge, Massachusetts, 403.

8. Fernandez DS, Ferraz RHS, Melo APF, Rodrigues RF, Souza WM (2010). Análise histológica das glândulas uretrais da capivara (Hydrochoerus hydrochaeris). Pesq Vet Bras 30(4):373-37.

9. Gotteich A, Hammel I, Yogev L, Terkel J (1996).Quantitative microscopic changes in the mole rat's accessory Sex organs duringan annual cycle. Anat Rec 246(2):231-237.

10. Gray H (2000). Anatomy of the Human Body. Lea\&Febiger, Philadelphia,1918; Bartleby.com, 2000. www.bartleby. com $/ 107 /$.

11. Holtz W, Foote RH (1978). The anatomy of the reproductive system in male Dutch rabbits (Oryctolaguscuniculus) with special emphasis on the accessory sex glands. J Morphol 158:1-20.

12. Hutson JM, Li R, Southwell BR, Newgreen D, Cousinery M (2015). Regulation of testicular descent. PediatrSurg Int 31(4):317-25.

13. Hutson JM, Nation T, Balic A, Southwell BR (2009). The role of the gubernaculum in the descent and undescent of the testis. Therapeutic Advances in Urology 1(2):115-121.

14. Jacob S, Poddar S (1986). Morphology and histochemistry of the ferret prostate. Acta Anat 125:268-273.

15. Knoblahgh S, True L (2011). Comparative Anatomy and Histology: A Mouse and Human Atlas. Elsevier Science, Burlington, 285-309.

16. Linnetz LJ (2000), Abdominal approach to castration in a prairie dog. Exotic DVM 2(5):19-22.

17. McCracken TH, Kainer R, Carlson D (2008). Color Atlas of Small Animal Anatomy: The Essentials. Blackwell Publishing, USA, 72.

18. Mollineau WM, Adogwa AO, Garcia GW (2009). The Gross and Micro Anatomy of the Accessory Sex Glands of the 
Male Agouti ( Dasyprocta leporina ). Anatomia, Histologia, Embryologia 38:204-207.

19. Mollineau W, Adogwa A, Jasper N, Young K, Garcia G (2006). The Gross Anatomy of the Male Reproductive System of a Neotropical Rodent: the Agouti (Dasyprota leporina). Anatomia, Histologia, Embryologia: Journal of Veterinary Medicine Series C 35(1):47-52.

20. NAV Nomina Anatomica Veterinaria, fifth edition, 2012.

21. Nishino T, Wedel T, Schmitt O, Biihlmeyer K, Schönfelder M, Hirtreiter C, Schulz T, Kiihnel W, Michna H (2004) Androgen-dependent morphology of prostates and seminal vesicles in the Hershberger Assay Evaluation of immunohistochemical and morphometric parameters. Ann Anat 186: 247-253.

22. Pelletier G (2002). Effects of estradiol on prostate epithelial cells in the castrated rat. J Hist Cytoc 50(11):1517-1523.
23. Pinheiro PF, Almeida CD, Segatelli TM, Martinez M, Padovani CR, Martinez FE (2003). Structure of the pelvic and penile urethra relationship with the ducts of the sex accesory glands of the Mongolian gerbil. J Anat 202(5):431-444.

24. Quesenberry K, Carpenter JW (2012). Ferrets, Rabbits and Rodents: Clinical Medicine and Surgery, 3 ed.

25. Suckow M, Weisbroth S, Franklin C (2005). The Laboratory Rat, Second Edition (American College of Laboratory Animal Medicine), Academic Press, Toronto.

26. Vasquez B, Del Sol M (2002). Complejo prostatico en el conejo (Oryctolaguscuniculus). Rev Chil Anat 20:175-180.

27. Weir BJ (1974). Reproductive characteristics of hystricomorfh rodents. Symp Zoology Soc London 34:265-446. 